\title{
The Relationship of Home Renovation and Gender at Suburban Housing of Semarang City in Indonesia
}

\author{
Landung Esariti ${ }^{A^{*}}$, Marsella Putri ${ }^{\mathrm{A}}$, Fitri Fauziah ${ }^{\mathrm{A}}$, Diah Dewi ${ }^{\mathrm{A}}$ \\ Received: February 14, 2021 | Revised: May 24, 2021 | Accepted: May 27, 2021 \\ doi: 10.5937/gp25-30861
}

\begin{abstract}
The purpose of this study was to explore gender influence on home renovation based on family life cycle in suburban housing of Bukit Kencana Jaya Semarang, Indonesia. Sixty households were interviewed and the resulting data were analyzed using the mix method. This attempt is important to determine the gender roles and relations influencing housing demand policies. The result showed most renovation activities were conducted on families with children, in addition to formulating two deductions. First, in single and new couples, gender productive roles tend to support house function in terms of economic existence and societal perception. Second, in families with children and elderly, these utilities serve as a habitat for income sources and welfare support.
\end{abstract}

Keywords: family life cycle; gender; home renovation

\section{Introduction}

The definition of gender covers the social interpretation applied to differentiate men and women during family and community interactions (Wieringa, 1998; Sullivan, 2004). This concept appears naturally flexible and is location based depending on religion, culture, public structure and educational status influencing individual mindset as well as community response. Under these circumstances, the development of persons is an important factor in observing the performance of gender relations roles. Gender relations play siginificant functions in participation and decision making for family subsistence (Soeharso \& Kusumowidagdo, 2016; Rotman, 2005). A common instance involves the determination of the specific area to revamp and is possibly influenced by the family head, regardless of mutual relationship or power difference. One party appears more dominant, compared to the others. The outcome forms one of the identities representing gender relations. Moreover, gender refers to a regular activity (Tjørring, 2016), although is also about decision making in this paper. Therefore, households are viewed as individuals responsible for the decisions in the renovation. Furthermore, gender also relates to age, sex, family structures and power relations within the home.

The negligence of space requirements during house acquisition is mainly responsible for the potential adjustments. Based on Agusniansyah \& Widiastuti (2016), the average Indonesian residence has experienced certain alterations in physical conditions, due to space demands. These circumstances are caused by the increasing family size, changing in marital status, and household structure (Clark \& Onaka, 1983). A positive response involves initial design modification to accommodate the space diversification.

\footnotetext{
A Urban and Regional Planning, Faculty of Engineering, Diponegoro University, Prof Soedharto SH Street, Tembalang, Semarang, Indonesia

* Corresponding author: Landung Esariti; e-mail: landungesariti@lecturer.undip.ac.id; Tel: +62821 38757228
} 
Home renovation is closely related to the influence of family life cycle to utilize space. The life cycle includes the developmental stages comprimising single, new, and household with children and elderly persons. This concept determines the extent of adjustment. For instance, in single setting, the bedroom assumes the most important segment to maintain the functional quality and performance, as well as typically serves as a favourite space to relax. Meanwhile, families with children exhibit various habits and patterns. Also, the characteristic of space utilization is related to health care concerns (Davey, 2006; Fischer \& Khorunzhina, 2014). For instance, the major renovation is performed in the kitchen. Moreover, the common pattern involves creating an additional room or converting the space from the terrace to a living room. This adjustment is due to additional activities in an effort to improve family life quality, e.g. children education events (Tupenaite et al., 2010). This description clarifies the relationship between gender and home development in terms of how to improve the quality of family life. However, recent researches have not comprehended the correlation between gender and home renovation, but on the decision influencing factors, including economic and environmental considerations. Meanwhile, gender determinants on reconstruction focused extensively on the performance of gender role and relations. For example, older persons tend to maintain the original house design, compare to relocating to a smaller shelter. The gender role in a domestic space is connected to the decision maker, as regards the renovation and also implementation (Knodel et al., 2005). This position covers the expected behaviours, values and attitudes appropriate for male and female. Three varying gender roles are assigned within a family, termed productive, reproduc- tive and community (Munro \& Smith, 1989; Kaufman, 2000). Productive roles are associated to the income of family members, specifically, the household head, and are also conducted inside and outside the environment. Meanwhile, the reproductive aspects represent parental upbringing, child bearing and domestic chores. These situations are also in terms of nurturing and generally describe the feminine positions. Lastly, community roles depict the associations between family members and the surroundings, in addition, to the external communication patterns, or network creation for family sustenance.

Moreover, gender relations consider the home personality of the rooms requiring renovation (Hasell \& Peatross, 1990). These measures refer to individual interactions with others, and are observed from the interpretation of assigned functions, including decision making and welfare. In a family context, gender relations are also connected to power interactions, as well as the strong desire for control in people and family assets (Kandiyoti, 1988). However, in Indonesian culture, the relationship is geared towards patriarchy and extended families. This paper is aimed at exploring the influence of gender roles and relations on the home renovation decisions in Bukit Kencana Jaya housing complex. This location is occurs in a low and middle housing facility in Tembalang district, Semarang city. The diversification of house types and the length of the occupancy are the primary reasons for the present research. Furthermore, the sample area comprises 110 hectares, and 6 sub-complexes. Based on the master plan for Semarang, between 2010-2030, the research location has become one of the developing areas at suburban districts with the main function of a sub-city settlements with low - medium density.

\section{Data and Methods}

The gender determinants were identified as influencing factors in the decision to conduct home renovation, including the gender roles and relations of family members. Gender roles and relations also include the individual conditions related to the level of education, sex, job type, income and assets ownership (Rotman, 2005; Safran-Norton, 2010). In addition, gender influence is also visible in the analysis of family perceptions towards house function as a means to enhance life quality (Munro \& Smith, 1989; Shrestha, 2000), and is adjusted to fit the family life cycle.

This paper employed a mixed method, described as a combination of quantitative and qualitatitive analysis. Initially, quantitative approach was employed to determine the sample quota and location, followed by the qualitative process involving interviews and field observations. Based on preliminary survey in March 2020, the location of Bukit Kencana Jaya Housing complex comprises six clusters, including Bukit Mutiara Jaya 1, Bukit Mutiara Jaya 2, Bukit Mutiara Jaya 3, Bukit New Mutiara, Bukit Saphire Jaya and Bukit Permata Jaya. Also, a convenient sample technique was derived to yield sixty respondents. The survey was performed during the coronavirus pandemic, where physical and social distancing were enacted. Furthermore, sixty participants were considered to have represented the total population, as the proportion of the number was in accordance with the size of the sample house types.

Interview questions were composed of three aspects, including profile identification related to gender 

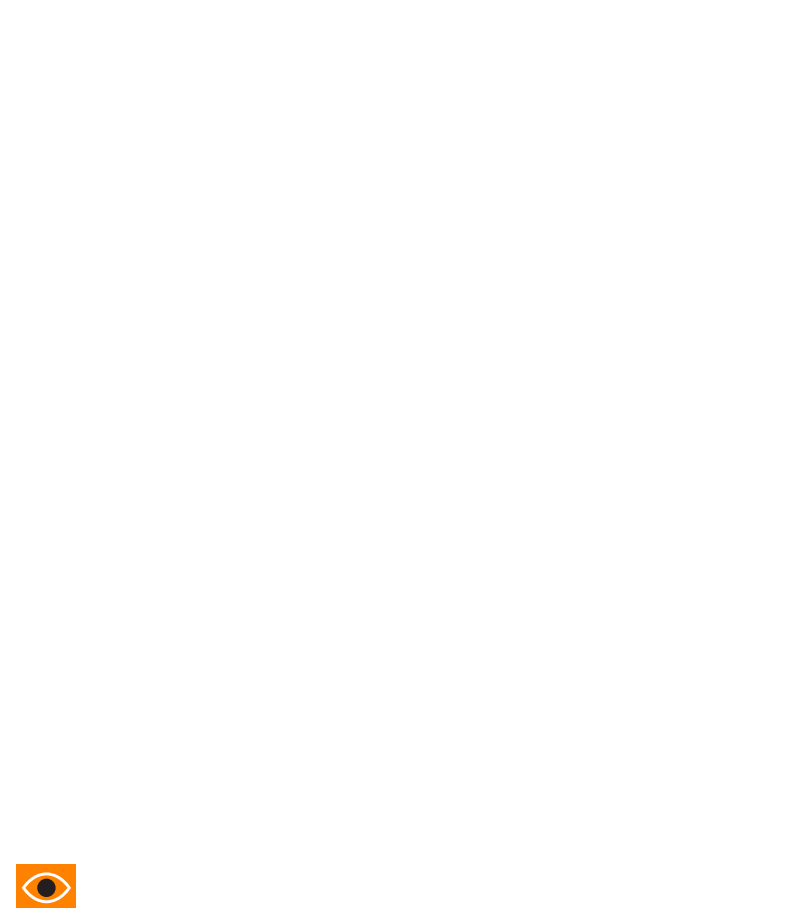

Figure 1. Location of the study area and sample distribution [click on figure to zoom]

attributes, detail information on renovation and considering factors in the first home purchase. The detailed outline of the interview questions are as follows.

This paper included three analysis stages, using descriptive and explanatory technique. The first involved the evaluation of home renovation typology for each family life cycle, while the second and last were based on the influence of gender roles and relations to home renovations, respectively. Therefore, in terms of the four types of family life cycle, it is necessary to observe an operational definition termed, single as
Table 1. Interview Guidelines

\begin{tabular}{|c|c|}
\hline Part & Questions \\
\hline \multicolumn{2}{|l|}{ A } \\
\hline \multirow{5}{*}{ Profile Identifications } & $\begin{array}{l}\text { Sex, age, educational background, } \\
\text { income, family member size }\end{array}$ \\
\hline & Home ownership status \\
\hline & Land status \\
\hline & Length of occupation \\
\hline & Buying mechanism (cash/credit) \\
\hline \multicolumn{2}{|l|}{ B } \\
\hline \multirow{6}{*}{$\begin{array}{l}\text { Home Renovation } \\
\text { Activities }\end{array}$} & Land plot area \\
\hline & Housing type \\
\hline & The number of bedrooms \\
\hline & The number of bathrooms \\
\hline & Part of house to be renovated \\
\hline & Renovation motivation \\
\hline \multicolumn{2}{|l|}{ C } \\
\hline \multirow{6}{*}{$\begin{array}{l}\text { Consideration } \\
\text { Variables In Buying } \\
\text { First Home }\end{array}$} & $\begin{array}{l}\text { The number of bedrooms and } \\
\text { bathroom to meet the family needs }\end{array}$ \\
\hline & Yard availability \\
\hline & Business space accessibility \\
\hline & Amenities \\
\hline & Access \\
\hline & Environment conditions \\
\hline
\end{tabular}

the unmarried house owner, new family as a recently married couple without any children, families with children as household in the medium family developmental stage, mostly with 2-5 offspring, while elderly as family members of over 65 years old living alone or with spouses, but the children reside separately and independently.

\section{Results and Discussions}

\section{Analyis of Home Renovation Typology}

Family composition tends to influence the housing demands, and is strongly based on the degree of economic conditions (Karsten, 2007). Clark and Onaka (1983) complemented the report of marital status and family composition as greatly impacting housing demands. Furthermore, field observations showed significant variations in home renovation activities based on the family life cycle.

The first group refers to singles, where the most important aspects in determining home ownership include marital status, house costs, and work experiences. Also, the activities of these individuals involved excess time consumption outside the home, in terms of long working hours, hangouts, and other outdoor fun engagements ( $\mathrm{Wu}, 2010)$ Therefore, single groups do not oblige to effect home renovations,e.g creating additional bedrooms or upgrading house floors, as interviews data showed a significant satisfactory level.

The second type describes the new families, where changes in marital status are a very influential decisive factor in house ownership and reconstruction (Wu, 2010). Field observation data emphasized the major facelifts to include the transformation of a garden into a terrace as a business startup workspace. However, the variety of business involved the opening of food shops, laundries, and water refill services. Furthermore, the economic motive appears as a very strong determinant in shaping the behavior of new family groups. This is consistent with the interview data, where majority of responses showed the income level as the most important factor in home ownership. 

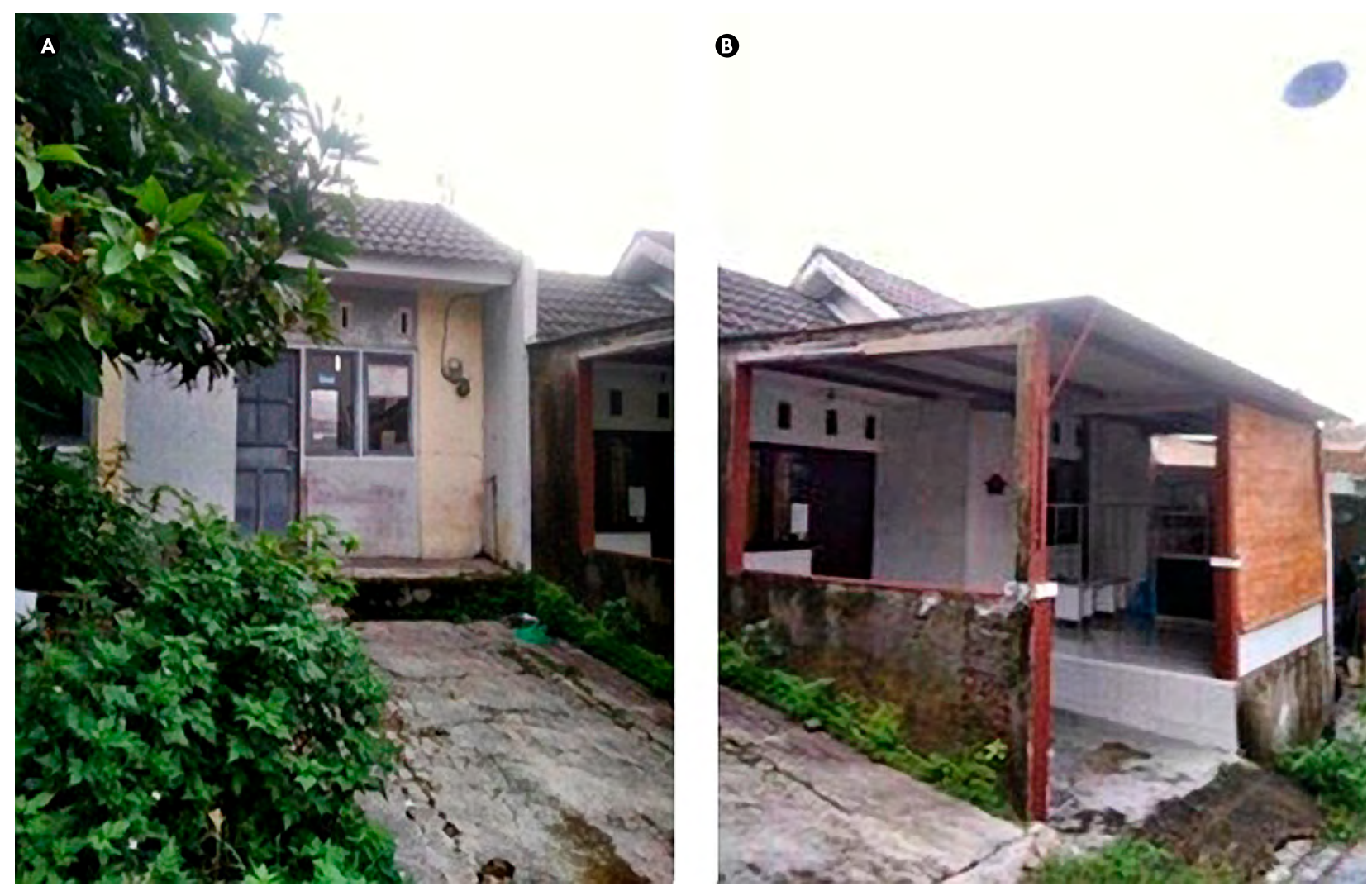

Figure 2. Example of types of physical adaptation according to family life cycle A - For single - original design preservation

B - For new family - terrace is used for home based business

The third is a family with children commonly residing in smaller shelters, with an area of $21-22 \mathrm{~m}^{2}$ in the research location. This condition is due to high income allocation to consumption needs, in terms of feeding, school fees, and future savings costs (Tan, 2012). Therefore, the group does not have sufficient funds to acquire larger houses. In line with the family structure growth, it is necessary for home renovation to accommodate the increasing space requirements. The survey data clearly showed over $91 \%$ of respondents from families with children performed renovations, while the remaining were in rented houses. Furthermore, the variety of changes encompassed additional bedrooms, bathrooms, building floors and kitchen expansion.

Lastly, elderly families are less probable to effect home renovations. Apart from the declining house size, the renovation have probably been initiated during the family with children stage. This category generally uses part of the home as a place for self-actualization and field observations showed the active role in assisting neighbors with child care and other nurturing activities. As an evidence, elderly families are known to open child care and shuttle services for school children. These efforts foster a sense of selfconfidence in the ability to demonstrate a productive role in economic terms. In addition, the renovations commonly involved turning the yard into a garden.
This is proven to be positive for health maintenance and food sustainability (Hwang et al., 2011).

\section{Analysis of Gender Role Correlation to Home Renovations}

The gender determinants describe the urgency to accommodate family members requirements in a fair and proportional manner, depending on the roles and relations (Shrestha, 2000). Housing demands reflect family size, individual background, financial abilities and preferences. This search has become very personal as the types and conditions of each household vary in terms of family life cycle. In the single group, the entire respondents resided in a $21 \mathrm{~m}^{2}$ shelter. Also, previous research viewed single and young families to involve smaller accommodation, compared to families with children $(\mathrm{Wu}, 2010)$. Based on interview results of single group, house preferences were more influenced by workplace distance. This finding is in accordance with (Andersen, 2011), where single people tend to select houses with higher non-financial considerations, e.g. as related to ease of maintenance and access to places often visited. The discovery also supports the performance of gender role in a productive aspect. Furthermore, housing location is a very important concern for job opportunities and income generation activities (Munro \& Smith, 1989). 

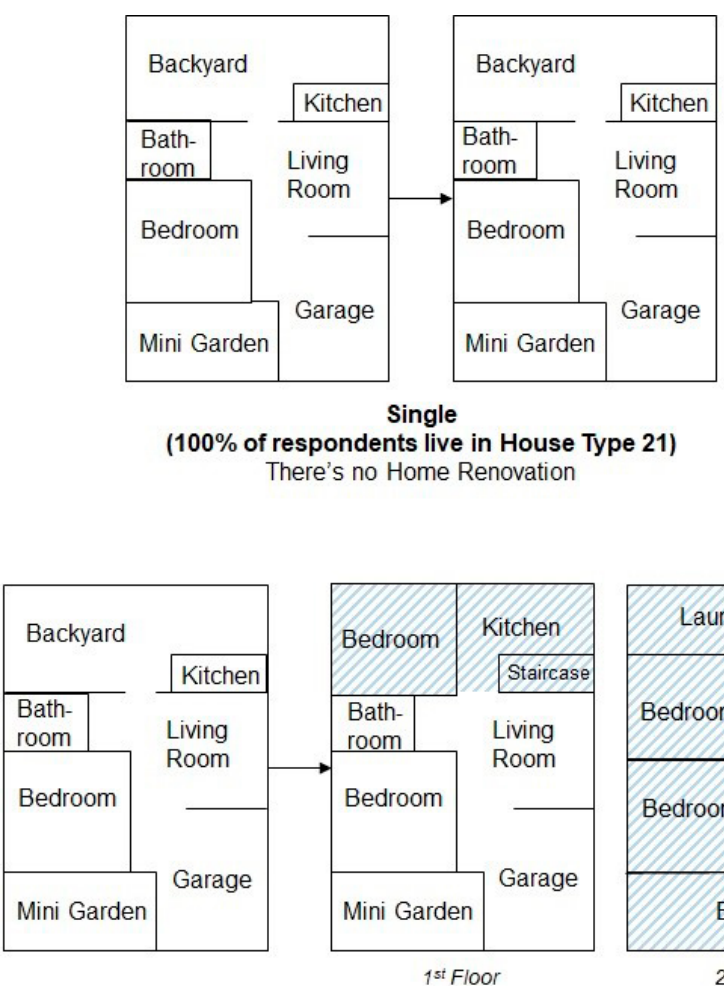

Family With Children

(Most of Respondents Live in House Types 21 and 22)

Additional Number of Bathrooms, Additional Number of

Bedrooms, Adding up Floor Space, Floor Plan Modification, and Kitchen Extension

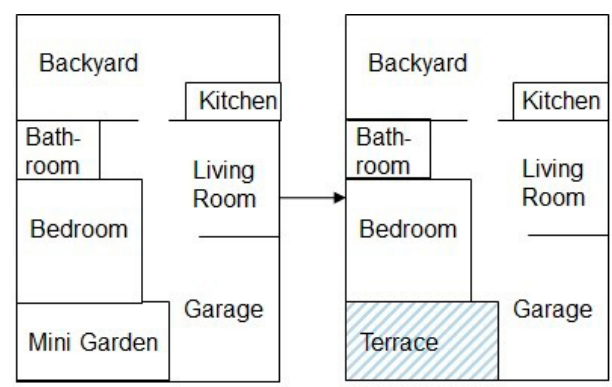

New Family

(Most of Respondents Live in House Type 22)

Optimal Function of Terrace for Business Activities

\section{Legend}

Home Renovation

Figure 3. Home Renovation Pattern For Each Family Life Cycle

The overall respondents in the new family group have lived separately from parents. In addition, the need to be independent encourages the plan to acquire a house more suitable with family development. This shows marital status occurs in a close relationship with home ownership as stated by (Fischer \& Khorunzhina, 2014). The renovations possibly involve widening of kitchen space and the need for a terrace/front yard for socialization purposes. As a consequence, recognition forms a representation of identity and position within the community. A presence of a terrace also serves as a place for home business activity to support family income. Field findings showed 33 and $67 \%$ of respondents reside in a 21 and $22 \mathrm{~m}^{2}$ apartment, respectively, and were classified as small types. Also, the results revealed similiar pattern with the single group, where gender productive role was more profound than community involvement. The renovation of terrace supports the reason for income earning activities. However, the primary residential selection factor in the new family category was the distance to school. This clarifies the acknowledgement of future needs, depending on additional family members. Furthermore, the prospective gender reproductive role has been carefully considered.

Families with children mostly dwell in small shelters of 21 and $22 \mathrm{~m}^{2}$, contrary to the need for a bigger house unlike the single and new families ( $\mathrm{Wu}, 2010$ ). Tan (2012) reportedly agreed to the previous research and further stressed the relationship of home ownership to household size, but the possibility is actually eroded by feeding and family health needs. Additional children in a family reduces the possibility of buying a house. Interview results showed families with children in smaller accommodations as there are surplus needs to fulfil, including the excess home purchase loans. Therefore, to anticipate the change in household size, renovations were initiated. As proven, $91 \%$ of the respondents in families with children performed embarked on the reconstruction. Meanwhile, the rest were unable to afford the opportunity, due to occupying rented houses, and are in limited financial conditions. Families with children experiencing divorce showed a tendency to change accommodations, using the rental system. Moreover, interview results supported (Clapham, 2009), where divorce is 
believed to influence family financial conditions, as home ownership appears very significant (Fischer \& Khorunzhina, 2014). Therefore, the possibility of divorce is also a high stake in house purchase, as well as uncertainty in revenues, house prices and financial assets. The impact of this situation caused the inability to acquire a house by loan or cash. In addition, divorced and non-divorced conditions are examples of gender role influence, as it determines house preference, as well as the renovation. Furthermore, the pattern of the revamp motive in family with children denotes a gender reproductive role. Therefore, family livelihood, child rearing and income stability significantly contribute to home reconstruction.

Based on the acquired data, $87.5 \%$ of elderly families occupied personal houses and the remaining $12.5 \%$ were in rentals. The house sizes varied between 21,42 , and $45 \mathrm{~m}^{2}$. This proves the existence of elderly families in massive houses. Painter \& Lee, (2009), however, argued the changes in health status and age instigated the reduction in home ownership maintenance, and were also responsible for the transition to smaller housing units. Elderly families in 42 and $45 \mathrm{~m}^{2}$ tend to preserve existing design, despite being separated from the children. The primary reason was to maintain the rooms for the visitation of the children and grandchildren. These particular groups regard a comfortable environment and yard availability as very significant.

Based on interview results, the availability of kindergartens and primary schools are main considerations for house preference among elderly families. The dependency on the two facilities is important in the opening of child care centers and shuttle services for school children. These activities are predominantly conducted by elderly families in personal residences. Another positive impact from the use of existing space is the ability to socialize and build relationships with neighbors (Martin-Matthews, 2007). For instance, the outdoor space possibly serves for social functions, including recitation, reading corner, knitting lessons and other handicraft activities. The observations also showed a more dynamic housing development in the elderly family group (Hwang et al., 2011). Under this circumstance, the house serves as a place for reciprocal connection with the environment, in terms of a mutual social relations with neighbors and the use of yard for community events. In general, community role appears more dominant, compared to reproductive and productive positions for elderly persons.

\section{Analysis of Gender Relation To Home Renovations}

Gender relation is determined by the household structure, including nuclear or extended. In addition, the concept is also influenced by the number of family members and patriarchal cultural factors. According to Sakina (2017) and Kandiyoti (1988), a patriarchal culture continues to develop within the framework of Indonesian society. This philosophy appears in various spheres, termed, economics, education, politics and also law. In the scope of home renovation, patriarchal culture is perceived from household decision making. However, in practice, the majority of conclusions are achieved by men as the family head (Holmes $\&$ Jones, 2010). This is very pronounce in situations where the only income source originates from the husband. Therefore, women tend to increasingly lack the courage to partake in household decision making.

This phenomenon existed during decision making on house segments to renovate. Moreover, men are commonly known to decide without discussion and agreement with the women/wives or other family members. This is culturally accepted as there is a general mindset where decision making powers reside in husbands. However, the situation has resulted in increased limitations of women participation in similar processes, including the determination of the home area to renovate.

The difference in power relations between husband and wife instigates imbalanced preferences. Conversely, the women are expected to prioritize the kitchen as a high value space (Shrestha, 2000). This reason is due to longer duration spent in the kitchen, as the unit determines cleanliness, health and resilience. As a consequence, poor women involvement in decision making is constantly neglected. Interview results concluded the control over decision making was influenced by access to gender productive roles. Moreover, a solid relationship exists between access to decision making and income level of individual family member (Munro \& Smith, 1989). Higher earnings correspond to an extensive power in this context. Figure 3 shows the results of field observations and interviews, and obviously supports the decision making within the household, as determined by the amount of savings. In addition, the priority of achieving renovation is greatly influenced by effective funding. Concurrent and fast reconstruction is possible with relatively large resource availability.

In a continuing basis, women tend to become insecure about self-actualization at the family and community levels. This is probably resolved by holding family discussions. However, for families with secondary education and above (high school and tertiary graduates), a culture of interaction is manifested in the use of shared space (Knodel et al., 2005). For instance, in families with children, everyone mutually agrees on the room to renovate. Figure 3 denotes the process of home renovations as collectively decided by family members. 


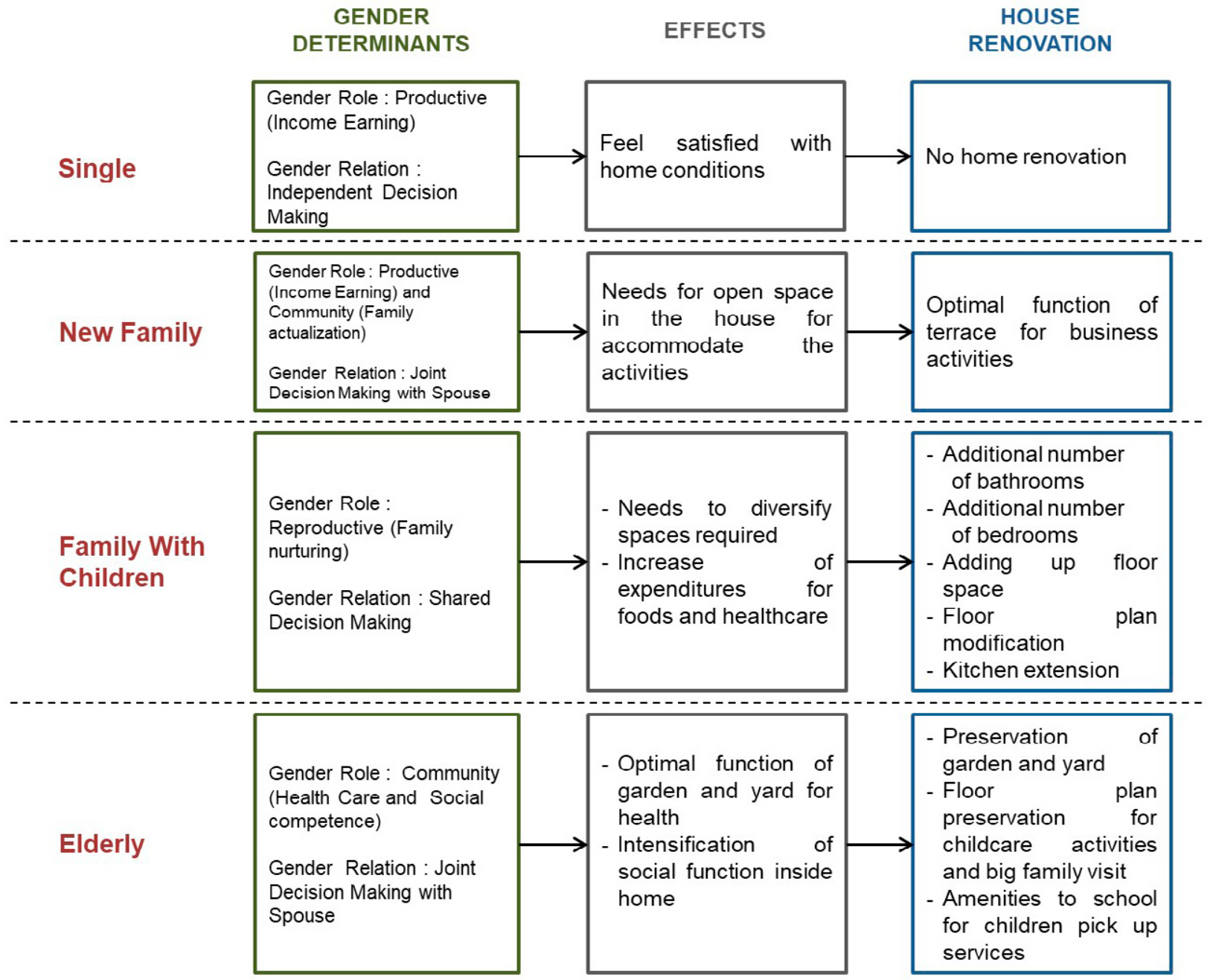

Figure 4. The correlation of gender role and gender relation, family life cycle, and home renovation

The need for various space types in families with children is also determined by environmental and cultural indicators (Hasell \& Peatross, 1990). In extended families, the living room serves as a semipublic space. Therefore, the renovation pattern is to preserve the space in a living room, but the usage increases. There are additional purposes to jointly applied in a living room, including a place for receiving guests and also for family benefit.

\section{Conclusion}

Based on interview results and discussions, changes in housing conditions were dependent on family development dynamics. This was indicated by the characteristic variations in the four family life cycle stages. However, households without any renovation plans due to financial constraints, marital status and ownership issues, were also prevalent.

The gender determinants, including the roles and relations, showed the houses were expected to serve as an identification of family social status, as well as individual capacity enhancement and community development. In addition, gender roles are related to the extent of responsibility demonstrated by extended members and also the optimal contribution to the success of the family structure. Meanwhile, gender relations determines the conditions, discussions, participation and cooperation required to achieve an improved life quality. Therefore, the relationship of gender determinants and house renovations were divided into two characteristics in Bukit Kencana Jaya complex. First, in singles and new families, the gender influence was based on the residential function in terms of maintaining social status, economic existence and family position. As a consequence, gender roles serve as productive and community functions. Second, in families with children and elderly persons, the focus was with respect to protection and welfare maintenance needed to support the fulfillment of ba- 
sic requirements and mental or spiritual health. Furthermore, a consolidation exists in the reproductive and community roles of a house as a significant in- strument in supporting livelihoods and fostering harmonious interactions with neighbors.

\section{Acknowledgement}

The author is grateful to the the Faculty of Engineering, Diponegoro University, Indonesia for financially supporting this research through Strategic Research Grant 2020.

\section{References}

Agusniansyah, N., \& Widiastuti, K. (2016). Konsep Pengolahan Desain Rumah Tumbuh [The Concept of Growing House Design]. Modul, 16(1), 1. https:// doi.org/10.14710/mdl.16.1.2016.1-12

Andersen, H. S. (2011). Motives for tenure choice during the life cycle: The importance of non-economic factors and other housing preferences. Housing, Theory and Society, 28(2), 183-207. https://doi.org/1 $\underline{0.1080 / 14036096.2010 .522029}$

Clapham, D. (2009). Introduction to the special issue - A theory of housing: Problems and potential. Housing, Theory and Society, 26(1), 1-9. https://doi. org/10.1080/14036090802704445

Clark, W. A. V., \& Onaka, J. L. (1983). Life Cycle and Housing Adjustment as Explanations of Residential Mobility. Urban Studies, 20(1), 47-57. https:// doi.org/10.1080/713703176

Davey, J. (2006). "Ageing in Place": The Views of Older Homeowners on Maintenance, Renovation and Adaptation. Social Policy Journal of New Zealand, (27), 128. Retrieved from https://www.msd.govt.nz/ about-msd-and-our-work/publications-resources/journals-and-magazines/social-policy-journal/ spj27/ageing-in-place-the-views-of-older-homeowners-27-pages128-141.html

Fischer, M., \& Khorunzhina, N. (2014). Family Composition and the Optimal Deman for Housing over the Life Cycle. Copenhagen Business School. https:// doi.org/10.3138/jcfs.12.3.365

Hasell, M. J., \& Peatross, F. D. (1990). Exploring Connections Between Women's Changing Roles and House Forms. Environment and Behavior, 22(1), 3-26.

Holmes, R., \& Jones, N. (2010). Overseas Development Institute: Rethinking social protection using a gender lens. Odi.

Hwang, E., Cummings, L., Sixsmith, A., \& Sixsmith, J. (2011). Impacts of home modifications on aging-inplace. Journal of Housing for the Elderly, 25(3), 246257. https://doi.org/10.1080/02763893.2011.595611

Kandiyoti, D. (1988). Bargaining with Patriarchy. Gender and Society, 2(3), 274-290.
Karsten, L. (2007). Housing as a way of life: Towards an understanding of middle-class families' preference for an urban residential location. Housing Studies, 22(1), 83-98. https://doi. org/10.1080/02673030601024630

Kaufman, G. (2000). Do gender role attitudes matter? Family formation and dissolution among traditional and egalitarian men and women. Journal of Family Issues, 21(1), 128-144. https://doi. org $/ 10.1177 / 019251300021001006$

Knodel, J., Loi, V. M., Jayakody, R., \& Huy, V. T. (2005). Gender Roles in the Family. Asian Population Studies, 1(1), 69-92. https://doi. org/10.1080/17441730500125888

Martin-Matthews, A. (2007). Situating "home" at the nexus of the public and private apheres: Ageing, gender and home support work in Canada. Current Sociology, 55(2), 229-249. https://doi. org $/ 10.1177 / 0011392107073305$

Munro, M., \& Smith, S. J. (1989). Gender and Housing: Broadening the Debate. Housing Studies, 4(1), 3-17. https://doi.org/10.1080/02673038908720639

Painter, G., \& Lee, K. O. (2009). Housing tenure transitions of older households: Life cycle, demographic, and familial factors. Regional Science and Urban Economics, 39(6), 749-760. https://doi.org/10.1016/j. regsciurbeco.2009.07.006

Rotman, D. L. (2005). Newlyweds, young families, and spinsters: A consideration of developmental cycle in historical archaeologies of gender. International Journal of Historical Archaeology, 9(1), 1-36. https://doi.org/10.1007/s10761-005-5670-0

Safran-Norton, C. E. (2010). Physical home environment as a determinant of aging in place for different types of elderly households. Journal of Housing for the Elderly, 24(2), 208-231. https://doi. org/10.1080/02763891003757494

Sakina, A. I. (2017). Menyoroti Budaya Patriarki Di Indonesia (Investigating Patriarchy in Indonesia). Share: Social Work Journal, 7(1), 71. https://doi. org/10.24198/share.v7i1.13820 
Shrestha, G. (2000). Gender Relations and Housing: A Cross-community Analysis. Gender, Technology and Development, 4(1), 61-86. https://doi.org/10.10 80/09718524.2000.11909952

Soeharso, D., \& Kusumowidagdo, A. (2016). Pengaruh Family Life Cycle Dalam Keputusan Memilih Desain Rumah Tinggal dan Lingkungan [Family Life Cycle Influence of Home and Environment Design Choice]. Jurnal Aksen, 1(2), 5-26.

Sullivan, O. (2004). Changing Gender Practices within the Household: A Theoretical Perspective. Gender and Society, 18(2), 207-222. https://doi. org $/ 10.1177 / 0891243203261571$

Tan, T. H. (2012). Meeting first-time buyers' housing needs and preferences in greater Kuala Lumpur. Cities, 29(6), 389-396. https://doi.org/10.1016/j.cities.2011.11.016

Tjørring, L. (2016). We forgot half of the population! The significance of gender in Danish ener- gy renovation projects. Energy Research and Social Science, 22, 115-124. https://doi.org/10.1016/j. erss.2016.08.008

Tupenaite, L., Zavadskas, E. K., Kaklauskas, A., Turskis, Z., \& Seniut, M. (2010). Multiple criteria assessment of alternatives for built and human environment renovation. Journal of Civil Engineering and Management, 16(2), 257-266. https://doi. org $/ 10.3846 /$ jcem. 2010.30

Wieringa, S. E. (1998). Rethinking gender planning: A critical discussion of the use of the concept of gender. Gender, Technology and Development, 2(3), 349371. https://doi.org/10.1177/097185249800200301

$\mathrm{Wu}$, F. (2010). Housing environment preference of young consumers in Guangzhou, China: Using the analytic hierarchy process. Property Management, 28(3), 174-192. https://doi. org/10.1108/02637471011051318 